\title{
The Covid-19 Pandemic and Meaning in Life
}

\author{
Aribiah David Attoe \\ https://orcid.org/0000-0001-9786-1824 \\ Centre for Leadership Ethics in Africa \\ aribiahdavidattoe@gmail.com
}

\author{
Jonathan O. Chimakonam \\ https://orcid.org/0000-0001-8913-1434 \\ University of Pretoria \\ jonathan.okeke@up.ac.za
}

\begin{abstract}
In the face of the Covid-19 pandemic, where death, sickness and suffering persist, there is some hint that there is nothing so special about the human race that particularly makes it immune to decimation. This is at odds with the general feeling that there is something significant, purposeful and/or meaningful about human life. Thus, the question that immediately comes to mind is whether the present pandemic and the negative situations it presents, destroy any hope of attaining meaning in life. In this article, we critically examine how the Covid19 pandemic affects meaning in life. While it is not far-fetched to assume that the pandemic, suffering, isolation, economic hardship, and so forth disrupt humanity's abilities at creating moments of meaning in life, it is our claim that it does not destroy it altogether, as many persons have found new ways of creating such moments, albeit small, through self-sacrifice/care, solidarity, and more. Finally, we conclude that in the face of this tragedy, what humanity can best hope for is the continuous creation of moments of meaning in life in order to reduce despair and sustain hope, however small. We expect that this article will foster future discussions about the impact of the Covid-19 pandemic on the question of meaningfulness.
\end{abstract}

Keywords: Covid-19; death; meaning; pandemic

\section{Introduction}

It can be argued that for many human beings, making judgments about the meaning of their lives is often suspended by the distractions of everyday activities. These distractions becloud the mind and allow the individual to not focus on making judgments about the meaningfulness of their lives and, then, what makes their lives meaningful. However, there are moments in a person's life where the noise and miasma of life's routine take a pause, and the individual takes a peek into the abyss; and wonders about the meaning and purpose of her existence. From the cold, silent contemplations of those moments of consciousness, emerges the uneasy question about the worth of our

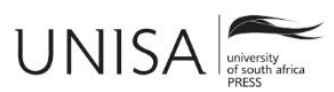


existence and the fleeting but the relentless terror that, perhaps, our lives as well as all our efforts, successes and attempts at meaningfulness are not only futile, but worthless.

These moments of silent contemplation usually manifest in moments of sober reflections and/or moments of great tragedy-whether personal or communal. These tragedies usually involve economic losses, sickness, suffering, or the greatest tragedy of all, death. It is no wonder that the book of Ecclesiastes, the most pessimistic book about meaning in the Christian Bible, is often read out at funerals and other moments of great tragedy. These tragedies particularly strike us because they puncture our sense of security and also deny us of those things we struggle hard for throughout our existence - our lives and our private property. At other times, we feel empathy towards others who have encountered these same tragedies, wondering if there is any reason to believe that such tragedies could not be our portions; if it could so debilitate others like us.

So, it is no wonder that in the present time, 2021AD, one cannot help but contemplatenot silently — on the meaning of our individual lives. What makes this "present time" particularly special is the fact that we are living through a pandemic - the Covid-19 pandemic - that has not only caused great economic tragedies and suffering among a vastly significant chunk of the human population, but has caused the death of countless individuals all around the world. Thus, we focus on the question of life's meaning in the face of the great tragedy that we currently face- the Covid-19 pandemic. However, unlike the contemplations of everyday folk, our approach to the topic of life's meaning is more nuanced and applies the critical rigour of philosophy.

The question of life's meaning is analysed through two perspectives, viz. the meaning of life, and meaning in life. While the former deals with the individual's life, taken as a whole, and whether that life can be considered meaningful, or humanity as a whole and whether there is a purpose to human existence. The latter concerns itself with those moments of meaningfulness that may dot an individual's life. While the pandemic affects how meaningfulness plays out in both senses ("meaning of" and "meaning in"), our primary focus is on "meaning in life" and how the Covid-19 pandemic disrupts attempts at gaining some meaning in life. We specifically argue that although "meaning in life" is challenged by the pandemic, it is not destroyed, because, somehow, the inventiveness of humanity has found different ways of creating moments of meaning for itself. We see/show examples of this inventiveness in the way human beings have sought to foster solidarity, harmony and fruitful relationships in digital spaces, despite measures to isolate. We also see/show how self-sacrificing deeds-in the actions of frontline workers who offer care, protection and the smooth running of society despite potential exposure to sickness, suffering and (maybe) death, and despite the natural instinct towards self-preservation-stand as moments of meaningfulness.

To properly delineate our views, we divide this paper into three sections. The first section attempts a definition of the concept of "meaning" as well as the senses in which 
we use the term meaning in life and the meaning of life. In the second section, we examine how the Covid-19 pandemic factors in with regards to claims about meaning in life. In the third section, we give examples of the inventiveness that shows that despite the peril of the present pandemic, meaning in life is still possible.

\section{Defining Meaning}

It is important to begin this article with a definition of what meaningfulness itself entails. This is because, for individuals who are unfamiliar with the concept of meaningfulness, we must explain what the term itself means, such that when one asks: "What is the meaning of life?" or "What constitutes meaning in life?" there is no confusion about what the question itself means. Furthermore, by delineating what "meaning" means, readers are immediately aware of the scope of actions and narratives that fall under the umbrella of meaningful acts - at least in relation to how we understand the term.

Meaningfulness is a complex concept and to ask about it is to first untangle what it means and how it is applied. It is quite normal for some individuals to declare that so and so an action or event, is meaningful. They might even go as far as to declare that a certain individual has brought meaning into their lives and then feel the deep sadness that comes with that person willingly leaving their lives or, worse, when that person ceases to exist. In such instances, the individual is merely pointing to instances of meaning that may dot their lives. These instances of meaning point mainly to what scholars of meaning usually refer to as meaning in life. Curiously, though, those moments of meaningfulness rarely allow us to make judgments about whether the individual's life, as a whole, is meaningful or meaningless. Consider the following as an example that makes this point clear:

Suppose a man spends most of his life trying to push a wall for no reason other than the fact that he has nothing to do. Suppose that that individual had cared for his mother for a short while, while she was ill, and went back to pushing a wall as soon as she got better.

In this example, we cannot deny that his care for his sick mother is a meaningful act, but we cannot also make the claim that this moment of meaningfulness gains the sort of traction that allows one to say that the individual's life as a whole - the majority of which involved wall pushing - is meaningful. Judging whether a life, taken as a whole, is meaningful, for us, points to questions about the meaning of life. ${ }^{1 .}$ What the above informs us of is that there are two senses of meaning, and each sense plays a role in our inquiry about the question of life's meaning in the face of the Covid-19 pandemic.

These two senses do not tell us about the meaning of "meaning" as yet. Scouring through the literature we became convinced about one fact. Monist theories of meaning such as

1 We recognise that the usage of the term "the meaning of life" usually refers to the meaning of human existence as a whole, or cosmic life as a whole. We prefer the present usage —which is similar to how Nagel (1987) uses the term — as it speaks more to the individual's life as a whole. 
purposiveness (Agada 2015; Mulgan 2015; Poettcker 2015), transcendence (Metz 2013; Nozick 1981), apt emotions (Metz 2001; Metz 2013), contributions to society (Martela 2017), and so forth - that is, definitions of meaning based on one single idea or principle-are much too narrow and do not capture every conception of meaningfulness. In other words, one can think up counter-examples of moments of meaningfulness that are, prima facie, meaningful, even though they do not capture the essence of the particular monistic theory in view. For instance, with regards to purposiveness, saving another person's life for the sake of it, and for no other reason, is a meaningful act, even though it does not tie to an overarching purpose. Also consider "contribution to society." A counter-example would be an individual who decides to practise on her own to become a musical virtuoso. Achieving the status of a musical virtuoso is something meaningful, whether or not the individual decides to play her music for the benefit of society or not. For want of space, we shall not go about providing counterexamples for every single monistic theory of meaningfulness out there, but the general point is that monistic accounts are notoriously narrow.

A pluralist concept of meaning would be the logical approach and one would find pluralist accounts in the works of Arjan Markus (2003) and Garrett Thomson (2003). The pluralist approach is also Metz's preferred approach when he presents what he terms "the family resemblance" approach. For Metz: "[T]o ask about meaning ... is to pose questions such as: which ends, besides one's own pleasure as such are most worth pursuing for their own sake; how to transcend one's animal nature; and what in life merits great esteem or admiration" (Metz 2013, 34). While this is a good attempt, we find that Metz's approach fails to capture two essential variables. The first variable is what we term "intrinsic subjectivity." Intrinsic subjectivity, for us, points to the subjective origins of the desire and acknowledgment of meaningfulness. This variable, thus, accounts for subjectivist accounts of meaningfulness, which the Metzian view does not account for. The second variable is purposive coherence. One immediately notices that Metz's account fails to bear on ideas about the meaning of life. Granted that his family resemblance approach is delineated in his book titled Meaning [in] Life, one would still imagine that his concept of meaning, since it ought to be all-encompassing, bears on the meaning of life too. Now, if one must consider an individual's life, taken as a whole, to be meaningful, one must first admit that there is something that ties the various actions and moments of that life together, and, second, one must admit that what ties that life together is an overarching goal to which that life coheres and makes sense. Thus, when we say this or that life, as a whole, has meaning, we are simply saying that there is an overarching goal or purpose to which this whole life purposively coheres. This same point makes sense even if we want to use the term "meaning of life" in the more conventional sense. There must be an overarching goal or purpose to which the existence of humanity and the various moments of human history ought to purposively cohere with in order for it to be considered meaningful. This is why we add purposive coherence to the mix.

So, we simply define meaning as follows: 
To ask about meaning is to pose questions such as: which subjectively pursued ends, besides one's own pleasure as such, are worth pursuing for their own sake; how to transcend one's animal nature; what in life merits great esteem or admiration; and what overarching goal or purpose ties meaningful actions in a life, taken as a whole, together into one comprehensible and coherent whole.

\section{Covid-19 and Meaning in Life}

We now have a fair understanding of what "meaning" means and, from here, we begin our contemplations about meaningfulness in the present times. First, there is no doubt that meaningful acts or moments of meaningfulness are possible — even in these present times. We see meaningfulness in the altruistic acts of those who care for those who are worst hit by the present pandemic. We see meaningfulness in the show of love that encapsulates our present desires to love our spouses or raise our children in such a way that they remain communally relevant. We do not intuitively think that the harsh realities of living with a pandemic diminish the quality of those acts, such that they become meaningless. In fact, if anything, one can speculate that this period has given some individuals the ability to express their humanness-Ubuntu, as most southern Africans would call it - in more ways than they did before.

This is a fair conclusion to make, but a deeper probe of these conclusions may question these very intuitions. The weaker critique is to imagine that in a pandemic such as this, more and more humans have become so economically handicapped that they can no longer transcend their animal nature, and only seek to survive. Statistics from the International Labour Organisation show that "Taken together, the vast majority, namely, $93 \%$, of the world's workers continue to reside in countries with workplace closure measures of some kind still in force" (International Labour Organisation 2020). There is the further prediction that " 1.6 billion informal economy workers could suffer 'massive damage' to their livelihoods" (World Economic Forum 2020). A significant chunk of individuals have lost their sources of income worldwide and, barring a massive bailout, which most governments are incapable of (whether for economic or corrupt reasons), they are in dire economic straits.

The reality of hardship is expressing itself in clear terms, and people who were comfortable in the past few years, are now aware that this relentless monster of poverty may be on their doorstep soon enough. Much of the pushback against lockdowns and the scramble to deny the lethal potency of the Covid-19 virus in (especially) North America, are direct fruits of this present reality. Of course, the obvious reply would be that not everyone will fall in the face of this monster, as there are other ways to secure one's economic status and avoid hardship. The other reply would be that for those who do experience this hardship, fighting to overcome the peril is something meaningful and so there is a change of transcendental priorities from going beyond one's animal nature to overcoming and going beyond those things that keep us below that animal nature. 
Unfortunately, there is a stronger critique. Suppose we throw subjectivity into the mix, then the power of death becomes more potent in denying us meaning - a painful thought in the face of a pandemic. We shall explain what we mean presently. Subjectivity, in the conventional sense in which it is used in the literature, is the idea that what is meaningful, depends on the individual or subject or whatever laid-down objective value the individual chooses as meaningful (Ayer 2008; Taylor 1970; Williams 2010). Here, we use subjectivity in a slightly different way. For us, it is the individual that intrinsically derives/pursues meaning, it is the individual that acknowledges the achievement of meaning and it is the individual who satisfies the claim to meaning. This is so for a number of reasons. In the first instance, attempts at meaningfulness that are merely instrumental — that is, externally imposed - are highly unattractive, since the individual who is involved is not invested in such an instrumental value, but only mindlessly accomplishes it.

The God-purpose view strikes us as an example of the point that we are trying to make. If we suppose that the meaning of our existence was to fulfil God's purpose and that our destinies only ensure that our lives take God's preferred trajectory, then the fact that we achieve God's purpose only tells us that the meaning we have achieved is not ours but God's, and so we cannot make sense of that meaning or call it our own because our lives are only meaningful to God and not ourselves. The intuition, then, is that we must be freely willing to adopt, derive and/or pursue a purveyor of meaning before we can exclaim: "X makes my life meaningful!" Second, the individual must be aware of the achievement of meaningfulness. If we suppose that the wall-pusher, in our earlier example, was suddenly conscripted into the army and singlehandedly won the war for his nation, which was formerly oppressed, but never saw this feat as anything meaningful to him but mere duty, and rather longed for his wall, such an individual would not say, "single-handedly winning the war made my life meaningful." Only those outside the individual, who find winning the war to be of value to them, can make such a claim. Again, such meaning makes sense to others outside the individual who possess the life, and not to the individual himself. External claims to meaningfulness, of this sort, cannot apply to the individual who must make the claim: "I am living a meaningful life." Indeed, our war hero wall-pusher might think his life miserable, absurd and meaningless (let us assume the war destroyed his wall) even though he may be praised by others. In this way, it only seems logical to include the subjective experience(s) of the individual whose life is being examined. The same argument applies to the satisfaction one gains by accomplishing a meaningful task/life, and it only goes to show the importance of subjectivity in any talk about meaningfulness.

If subjectivity is an important aspect of claims to meaningfulness, then what happens to our claims to meaning in life, if we are faced with death $?^{2}$ One can speculate that for most people, the denial in which they live, projects death as a far-off occurrence.

2 A person is dead if and only if the vital functioning of his/her biology is lost in such a way that not only is his/her brain in its entirety incapable of functioning at any level, his/her various supporting organs are also incapable of functioning at any level. 
Unfortunately, the Covid-19 pandemic only drags death closer to the present. According to the World Health Organisation, as at "09:45 am CEST, 3 February 2021, there have been 103,201,340 confirmed cases of Covid-19, including 2,029,084 deaths, reported to WHO" (World Health Organisation 2021). With infection rates soaring, it appears that no one is exempted from the possibility of sickness, suffering and death. If death implies the permanent cessation of an individual's subjective experience (see Chimakonam et. al. 2019, 88-89), could it not be said that meaning in life is cut short by death? If the present pandemic brings death much closer to our lives, could it not be said that the Covid-19 pandemic has enabled a much quicker demise of our claims to meaningfulness? The answers to these questions are difficult.

The difficulty lies mainly in the fact that while one must acknowledge a meaningful act while one is still alive, one must also, in the same breath, deny that those claims to meaning do not, ultimately, work. While such a seeming contradiction is not compatible with Western-styled two-value logics, it is well accommodated within the Ezumezu logical system from which we proceed-we must employ the context principle of Ezumezu logic (Chimakonam 2019, 99-100). The idea is this; while we can say of moments of meaning that these are instances of meaning, such a claim is not a static claim but a dynamic one. This is because life itself is not static, but continues to flow from moment to moment, eventually flowing into death and nothingness. When one claims that $\mathrm{X}$ is a moment of meaningfulness, one is really saying that $\mathrm{X}$ is a moment in life's flow that is meaningful, insofar as life continues to flow. However, life is not a constant flow. There is a limited amount of life that can flow and this flow empties into nothingness. Hence, there would surely be a time when all of life empties into nothingness and there is nothing left to flow. When this happens, there is no flow or moment to point to as meaningful. If one can no longer point to a moment of meaningfulness since the life flow, to which that moment resides, no longer exists, then one cannot say at that moment that there exists a meaningful moment $\mathrm{X}$ in the individual's life. It is the same way we do not stand in front of a dried-up riverbed and say "this is a river with fishes in it" - even though at some point in the past, such a thing existed.

The weaker reply would be that, perhaps, meaning in life is sustained in the eyes of others who outlive the individual and recognise his/her deeds as meaningful. Friends of the meaninglessness view would reply that if subjectivity is as important as we think it is, and if instrumental types of meaning are as unattractive as we think they are, then we must admit that communal acknowledgments must mean nothing to the individual (especially when that individual is dead). Beyond all these, human existence also flows, like human life, into a final death and nothingness. The eventual extinction of the human species makes this communal acknowledgment of meaning in life fall prey to the overall problem that death brings. Thus, from what we have said above, we see that the power of the present pandemic lies in its ability to threaten the flow of our existence and subjective experience, and so convert our claims to meaning, into nothing. 
But there is a stronger argument that might grant us a glimmer of hope. If we admit that meaning in life is possible, transient and momentary, then we must admit that even the dead enjoyed it when they were alive. Hence, like our dried-up river bed, although we cannot point to it and say a river exists here, such a claim does not make the closely related claim "there was once a river here," nonsensical. In the same way, while we cannot point to a dead body and say that it is achieving or capable of achieving meaning in life - mainly because of the loss of subjectivity - past instances of meaning remain historically relevant since we can always say, "while alive, there were instances of meaning in his/her life." The argument then suggests that while death eliminates subjectivity eventually, that impending dissolution into nothingness does not negate the relevance of current instances of meaning in themselves, in much the same way that the inevitable drying up of lake Chad does not negate its current relevance to those around the Chad basin.

\section{Covid-19 and the Possibility of Meaning in Life}

What the previous arguments allow, is the glimmer of hope that allows us to attach the possibility of meaning in life, even though such meaning is momentary and fleeting. Consequently, despite the death and nothingness that the present pandemic brings, one is allowed to believe that instances of meaning can be squeezed out of whatever life we may have left, even though the Covid-19 pandemic threatens to bring that death even closer. Indeed, specific to our present situation as well as the ingenuity of humans, some instances of meaning abound.

\section{From Communal Function to Digital/Virtual Communal Function}

In the African philosophical literature on meaningfulness the communal normative function theory stands out - especially since it builds on the dominant communal theories found in sub-Saharan Africa. According to the view, meaningfulness is expressed when we attain personhood (Menkiti 2004) by engaging in those acts that build positive relationships and engagements with others in the world, and also builds solidarity with one's own society and culture. According to Aribiah Attoe $(2020,136)$ :

Meaning in this sense would therefore consist in the individual's ability to acquire humanity in its most potent form through a sustained performance of those acts that foster harmony, avoid discord and promote the common good. Meaningfulness in this sense would involve a transcendent mindset that goes beyond our animal instincts to shed the pettiness of our animal desires. The purpose of human existence and what would be most desirable would be the attainment of full human flourishing.

From March 2020, when lockdown protocols began to be fully enforced all over the world, fostering harmony, communing, building positive relationships with others, showing solidarity with societal and cultural traditions, were all cut short by the fact that human beings were essentially isolated from each other during the lockdown period. One would think that gaining meaning in this way, during the height of the Covid-19 pandemic, cuts short this road to meaningful, but that has not been the case. Instead, the 
communal road to meaningfulness has been remodelled on the back of a world that has become more digital/virtual.

Intuitively, one can question the concrete ${ }^{3}$ nature of the virtual/digital world, especially when compared with the material world we live in. Indeed, when individuals relate with each other, such a relationship appears more concrete than virtual relationships between human avatars over, say, the internet. However, this questioning would be based on a wrong assumption, since the digital world is manned by human beings and the relationships that are fostered in this digital world have real-life consequences as they affect individuals in much the same way that physical relationships do, but with a greater reach.

Because individuals have had to isolate from one another, fostering harmony has become a digital affair. Due to the pandemic, individuals now form communities with others via digital apps like Facebook and WhatsApp. Individuals now seek to effect social change, even at a global level-even while in isolation. Acts of love, such as "giveaway challenges" became popular at the height of extreme lockdowns. Individuals sought to make other individuals happy with countless memes and video skits. People also sought to engage in certain social, cultural and religious rituals through apps that offered live video coverage and interaction such as YouTube, Zoom, and Skype. The desire to improve on one's own humanity and communal function through the sustenance of harmony, positive relationships and solidarity among individuals in this way, and despite the challenges involved, as well as the sustenance of communal, spiritual/religious and social rituals, is not only worthy of great esteem but is also an end worth pursuing.

\section{Self-sacrifice}

We also see instances/pursuit of meaningfulness in front-line workers who continue to function despite the dangers and exposure associated with doing so. Perhaps, there is no more persistent instinct among human beings - and living beings generally - than the instinct of self-preservation (and by extension self-interest). For Asouzu (2003), it is the underlying factor behind the ambivalence of human nature - that is, serving one's interest, even when we know we ought to take another line of action. The desire to take care of one's own interests first, panders to our continuous (near) automatic involvement in the evolution game of survival and reproduction. Despite this, we see individuals like delivery men/women (who work hard to make sure that important correspondence and other goods and services continue to reach the designated client); doctors, hospital cleaners, nurses, caregivers (who provide care and health services to the old and the sick); even entertainers (who try to lift spirits with their art), continuing to do their job even when that job means direct contact with, or potential exposure to, the highly infectious Covid-19 virus. Now, performing the task that these individuals do, does not involve coercion. Coupling this with the fact that these frontline workers are faced with

Concrete is used in the same sense as "real and physical." 
a choice between preserving their existence, or going to work and potentially contracting suffering/death for the sake of strangers, it is almost ridiculous that they choose the latter. However, by doing so, these individuals transcend their natural inclinations and their animal instinct to do something truly super-natural and meaningful - they engage in service to others at the risk of suffering and death.

Recall that we had previously talked about meaning in terms of: which subjectively pursued ends, besides one's own pleasure as such, are worth pursuing for their own sake; how to transcend one's animal nature; what in life merits great esteem or admiration. The self-sacrifice involved, here, nods at each of these pointers to meaning. By subjectively deciding to resist one's pleasure and self-interest in order to save life and keep societies going, these individuals are pursuing ends that are not only beyond them, but ends that are worth pursuing. Furthermore, these worthwhile ends, as we have shown, transcend our animal nature, and our instinct towards self-preservation. For those who put their lives on the line for the sake of others and for the sake of the continuous running of their respective societies, doing so places their actions on a pedestal that transcends mere instinct or duty, and settles on meaningful.

From the above, we see that the desire to not just exist but also squeeze out a meaningful existence, despite the pandemic, only projects the innate desire to pursue hope rather than retire to despair.

\section{Conclusion}

It is clear that meaning in life is not beyond our grasp, and that despite our present predicament (and despite the possibility of suffering and death that the Covid-19 pandemic presents) meaning in life is still possible. With the examples that we have provided, we have attempted to show some instances where meaning in life has played out in our fully ravaged world. Thus, whenever our present condition forces us to think and silently contemplate, that contemplation should do nothing more than remind us that as far as meaning in life is concerned, there is some hope. This reminder should also enable a move from mere recognition of hope to actual striving and pursuit for meaning in life.

What the Covid-19 pandemic implies for the meaning of life, is another matter altogether. Does death and/or suffering, such as the type brought about by the pandemic, make an individual's life, taken as a whole, meaningless? What does this mean for how to live? It is our preliminary suspicion that death plays an important role in undercutting the meaning of an individual's life, taken as a whole. These are, however, matters for future debates.

\section{References}

Agada, Ada. 2015. "Existence and Consolation: Reinventing Ontology, Gnosis and Values." In African Philosophy, edited by Jonathan Chimakonam. Minnesota: Paragon House. 
Asouzu, Innocent. 2003. Effective Leadership and the Ambivalence of Human Interest: The Nigerian Paradox in a Complementary Perspective. Calabar: University of Calabar Press.

Attoe, Aribiah. 2020. "A Systematic Account of African Conceptions of the Meaning of/in Life.” South African Journal of Philosophy 39 (2): 127-139. https://doi.org/10.1080/02580136.2020.1771822.

Ayer, A. J. 2008. "The Claims of Philosophy.” In The Meaning of Life: A Reader, 199-202. New York: Oxford University Press.

Chimakonam, Jonathan. 2019. Ezumezu: A System of Logic for African Philosophy and Studies. Cham: Switzerland. https://doi.org/10.1007/978-3-030-11075-8.

Chimakonam, Jonathan, Egbai Uti, Samuel Segun, and Aribiah Attoe. 2019. New Conversations on the Problems of Identity, Consciousness and Mind. Cham: Springer Nature. https://doi.org/10.1007/978-3-030-14262-9.

International Labour Organisation. 2020. "ILO Monitor: Covid-19 and the World of Work." June 30. Accessed August 3, 2020. https://www.ilo.org/wcmsp5/groups/public/@dgreports/@dcomm/documents/briefingnote/ wcms_749399.pdf.

Markus, A. 2003. “Assessing Views of Life: A Subjective Affair?” Religious Studies 2: 125143. https://doi.org/10.1017/S0034412503006425.

Martela, Frank. 2017. "Meaningfulness as Contribution.” The Southern Journal of Philosophy 55 (2): 232-256. https://doi.org/10.1111/sjp.12217.

Menkiti, Ifeanyi. 2004. "On the Normative Conception of a Person.” In A Companion to African Philosophy, edited by Kwasi Wiredu, 324-331. Oxford: Blackwell Publishing. https://doi.org/10.1002/9780470997154.ch25.

Metz, Thaddeus. 2001. “The Concept of a Meaningful Life.” American Philosophical Quarterly 38: 137-153.

Metz, Thaddeus. 2013. Meaning in Life. Oxford: Oxford University Press. https://doi.org/10.1093/acprof:oso/9780199599318.001.0001.

Mulgan, Tim. 2015. Purpose in the Universe: The Moral and Metaphysical Case for Ananthropocentric Purposivism. Oxford: Oxford University Press. https://doi.org/10.1093/acprof:oso/9780199646142.001.0001.

Nagel, Thomas. 1987. What Does It All Mean? A Very Short Introduction to Philosophy. Oxford: Oxford University Press.

Nozick, Robert. 1981. "Philosophy and the Meaning of Life." In Philosophical Explanations Robert Nozick, 571-650. Cambridge, MA: Harvard University Press. 
Poettcker, J. 2015. "Defending the Purpose Theory of Meaning in Life." Journal of Philosophy of Life 5: 180-207.

Taylor, Richard. 1970. "The Meaning of Life." In Good and Evil: A New Direction, edited by Richard Taylor, 319-334. New York: Macmillan.

Thomson, G. 2003. On the Meaning of Life. South Melbourne: Nelson Thomson Learning.

Williams, Bernard. 2010. "The Makropulos Case: Reflections on the Tedium of Immortality." In Life, Death, and Meaning: Key Philosophical Readings on the Big Questions, edited by David Benatar, 345-362. Lanham: Rowman \& Littlefield Publishers.

World Economic Forum. 2020. "How Coronavirus has Hit Employment in G7 Economies." May 13. Accessed August 3, 2020.

https://www.weforum.org/agenda/2020/05/coronavirus-unemployment-jobs-work-impactg7-pandemic/.

World Health Organisation. 2021. "WHO Coronavirus Disease (Covid-19) Dashboard." February 3. Accessed February 3, 2021. https://covid19.who.int/?gclid=Cj0KCQjw6575BRCQARIsAMpksOIsLB6yW7hNMhpNgQxWCZ6LQhHKV5HiNel2SF6IAKrzjKCiyFGloaAittEALw_wcB 